In most cases where gold or gold alloys are made to adhere strongly to oxygen-containing substrates, there is evidence of reaction bonding. In some instances, however, where strong bonds are formed between pure gold and these substrates, no evidence of reaction bonding has so far been obtained and the exact nature of the mechanism involved has still to be elucidated.

\section{References}

$1 \mathrm{M}$. Rosenberg, 'Geschichte der Goldschmiedckunst auf technischer Grundlage', Otto Zeller Verlag, Osnabrück, 1972

2 E. A. Smith, 'Working in Precious Metals', N.A.G. Press Ltd., London, 1933

3 Williams Gold Refining Co. Inc., U.S. Patent 3,769,006

4 J. N. Nally, Int. Dent. Assoc. F., 1968, 18, 309-325

5 Dr. Th. Wieland Scheideanstalt, German Offen. 2302837

6 F. Sperner, Z. Metallkd., 1976, 67, 289-295; F. Sperner and N. Harmsen, Mikrochim. Acta, 1977, Suppl. 7, 415-427

7 B. W. King, H. P. Tripp and W. H. Duckworth, f. Am. Ceram. Soc., 1959, 42, 504-525

8 E. P. Lautenschlager et al., 7. Dent. Res., 1969, 48, 1206-1210

9 M. Sz. von Radnoth, Dtsch. zahnärztl. Z., 1970, 25, 259-264

10 J. N. Nally, et al., Schweiz. Monatsschr. Zahnheilk., 1968, 78, 868-878

11 F. Chemnitius, f. Prakt. Chem., 1927, 117, 247-26

12 R. C. Langley, Gold Bull., 1975, 8, (2), 34-40
13 R. G. Finch, Gold Bull., 1972, 5, (2), 26-30

14 R. H. Caley, Gold Bull., 1976, 9, (3), 70-75

15 Anon., Gold Bull., 1975, 8, (1), 13-15

16 E. I. du Pont de Nemours \& Company, U.S. Patent 3,440,182

17 E. I. du Pont de Nemours \& Company, Dutch Applic. 6707540

18 G. J. Zydzik et al., Appl. Phys. Lett., 1977, 31, 697-699

19 S. Serizawa, fapanese Prelim. Publ. 77-129 637

20 D. M. Mattox, Thin Solid Films, 1973, 18, 173-186

21 E. W. Williams, Gold Bull., 1978, 11, (2), 30-34

22 G. Bustacchini, Gold Bull., 1973, 6, (2), $52-56$

23 L. Holland, 'Vacuum Deposition of Thin Films', Chapman \& Hall, London, 1961, p. 504

24 R. Groth and W. Reichelt, Gold Bull., 1974, 7, (3), 62-68

25 H. Schmidt-Brücken and W. Schlapp, Keram. Z., 1971, 23 (4), 191-198; (5), 278-280 and (12), 1-5

26 Annual Report, Division of Chemical Physics, CSIRO, Australia, 1976-1977

27 H. J. de Bruin et al., Gold Bull., 1972, 5, (3), 62-64; C. Varmazis, R. Viswanathan and R. Caton, Rev. Sci. Instrum., 1978, 49, (4), 549-550

28 F. P. Bailey and K. J. T Black, 7. Mater. Sci., 1978, 13, 1045-1052

29 J. A. Pask, Report LBL 602, Sandia Laboratories, Alburquerque, New Mexico, U.S.A., 21 Jan., 1977

30 B. J. Sitch, Gold Bull., 1978, 11, (4), 110-115

31 Sumitomo Bakelite Company Limited and T. Takagi, British Patent 1493088

32 I. Takemoto (Hitachi Ltd.), Japanese Preiim. Publ. 77-136 284 (Chem. Abstr., 1978, 88, 137610)

33 T. Nenodović et al., Thin Solid Films, 1976, 34, 211-214

34 O. W. Rogers and J. R. Griffith, Aust. Dent. F., 1977, 22, (5), $371-372$

\title{
Gold Plating with Pulsed Current
}

\section{PRESENTATIONS AT A RECENT SYMPOSIUM}

\author{
Frank H. Reid
}

Consultant, Werner Flïhmann AG, Duebendorf, Switzerland

\begin{abstract}
At an International Pulse Plating Symposium held under the auspices of the American Electroplaters' Society on April 19th and 20th, 1979, in Boston, MA., a number of papers was presented on the pulse plating of gold. The high promise for improved gold coatings prepared by this method of deposition is reflected by this review of current developments.
\end{abstract}

It is now almost a decade since interest in pulse plating as a technological rather than a pure research tool was stimulated by the work of Avila and Brown (1), who utilized pulses and rest periods in the millisecond range to improve the density and electrical conductivity of gold deposits for conducting paths in electric circuits. In the intervening period numerous papers have been published in this field (for example, the review by Raub and Knödler of the application of the technique to the plating of gold, Gold Bull., $1977,10,(2), 38-44)$ and investigational work has also extended into the plating of base metals, such as chromium, copper, zinc and cadmium.

As for all relatively new techniques, wide claims have been made concerning the benefits to be derived from electroplating with pulsed current ( $\mathrm{PC}$ ), and a principal object of the present Symposium was to provide a clear assessment of the actual 'state of the art', with reference to theory and industrial practicality. In this context, gold plating figured prominently, in view of the promise of more economic usage of the metal via improvements in properties.

Main interest centred on the widely used acid cyanide electrolytes containing cobalt additions. Knödler (2) presented the results of an extensive study of the effects of PC plating on the composition and some mechanical properties of deposits from gold-cobalt, gold-nickel and goldiron electrolytes, with the general conclusion that PC increases the base metal content and decreases the nonmetallic content of deposits, with significant variations of composition and properties possible under varying pulse conditions. Hardness is little affected, but tensile strength is reduced and brightness diminished. The results were interpreted in terms of an adsorption-desorption model on the lines of those proposed by Cheh (3) and Ibl et al. (4). The high hardness of direct current (DC) deposits was attributed to deposition of non-metallic material rather than to the hardening effect of alloying. 


\section{Effects upon Wear and Related Properties}

Other contributions covered the important question of wear properties. Branik and Schnabel (5) described the results of wear tests on connector blade assemblies plated with a number of coatings, selected on the basis of a preliminary survey of composition, surface condition and porosity of deposits over a variety of PC conditions and covering a range of carbon and cobalt contents as follows:

$\begin{array}{lccc} & \begin{array}{c}\text { On/Off } \\ \text { times } \\ \text { ms }\end{array} & \begin{array}{c}\text { Co } \\ \%\end{array} & \begin{array}{c}\text { C } \\ \%\end{array} \\ \mathrm{DC}\left(1 \mathrm{~A} / \mathrm{dm}^{2}\right) & - & 0.17 & 0.34 \\ \mathrm{PC}\left(2 \mathrm{~A} / \mathrm{dm}^{2}\right)^{\star} & 2.5 / 3.0 & 0.10 & 0.33 \\ \mathrm{PC}\left(7 \mathrm{~A} / \mathrm{dm}^{2}\right)^{\star} & 2.5 / 20 & 0.13 & 0.18 \\ \mathrm{PC}\left(22 \mathrm{~A} / \mathrm{dm}^{2}\right)^{\star} & 2.5 / 65 & 0.35 & 0.04 \\ \text { *peak values } & & & \end{array}$

The coatings were operated against spring contacts carry ing a clad inlay of a proprietary hard precious metal contact alloy, for 200 insertion and withdrawal cycles with continuous monitoring of insertion and withdrawal forces (DIN 41612). Wear tests were supplemented by corrosion tests in which contact resistance was measured before and after exposure to a hydrogen sulphide/sulphur dioxide at mosphere. Insertion and withdrawal forces were marginally lower for one PC $\left(2 \mathrm{~A} / \mathrm{dm}^{2}\right)$ sample as compared with the DC deposit, but considerably higher for the PC coatings produced at higher duty cycles, indicative of adhesive wear, which was confirmed by scanning electron microscopy (SEM) of surfaces. The authors related the wear results to the carbon content of coatings, on the view that carbon released by friction acts as a dry lubricant.

In contrast to this, Reid et al. (6) discussed the wear characteristics of DC and PC deposits in terms of structural features as revealed by high resolution transmission electron microscopy (TEM) on coatings after electrolytic thinning to about $100 \AA$ A. DC coatings produced at $1 \mathrm{~A} / \mathrm{dm}^{2}$ showed very small average grain size (about $250 \AA$ ) and extremely high frequency of pores or inclusions, in the order of 2 to 3 $x 10^{19} / \mathrm{cm}^{3}$. These ranged in diameter from 5 to about $60 \AA$, giving an average weighted diameter of $25 \AA$, corresponding to a total pore volume of some 10 per cent. PC (10 ms on/100 ms off) gave coatings with larger grain size (about $1000 \AA$ ), completely free from inclusions and with dislocations visible inside the grains. These features readily explain the high density, high ductility and high electrical conductivity of PC as compared with DC coatings.

Wear resistance was assessed by SEM observation of wear tracks produced in sliding between crossed rods as used in contact resistance measurement. This indicated negligible wear in either case at loadings up to about $200 \mathrm{~g}$, but gave a sharp differentiation at a loading of $500 \mathrm{~g}$, under which the DC coatings maintained excellent wear resistance while the PC coatings failed rapidly by adhesive wear. The results were related by the authors to elasticity/hardness factors governing the transition of contact deformation from elastic (low wear) to plastic (high wear) regimes. The excellent performance of the DC coatings was ascribed to the submicroscopic hardening effect of the non-metallic inclusions, which also serve to stabilize the fine-grained structure, even at temperatures up to at least $300^{\circ} \mathrm{C}$. For the $\mathrm{PC}$ coatings the elasticity/hardness factor favours earlier transition from elastic to plastic deformation under load and the effect is further enhanced due to recrystallization and softening of the inclusion-free coatings at elevated temperatures which can easily develop locally in sliding contacts. Adhesive wear is also favoured in the case of the PC coatings by relative surface roughness and the absence of foreign material which might hinder cold welding.

Compositional and structural features were also discussed by Stimetz and Hren (7), who presented SEM studies of surface structures and TEM studies of films about $1000 \AA$ thick. Results confirmed an increased cobalt content for PC deposits, but these authors found no significant difference in microstructure between conventional and PC coatings and no tendency for preferred orientation in either case. Attention was directed to differences in the density of growth twins between coatings produced with a 50 per cent duty cycle and those obtained with a lower (33 per cent) duty cycle or with DC, but the significance of this feature in relation to physical, mechanical and electrical properties is not yet clarified.

\section{Experience of Large Scale Applications}

Of major applicational interest was a paper by Leaman and Kownacki (8) presenting comprehensive data covering an exhaustive comparison of DC and PC plating of goldcobalt deposits in a continuous plating installation, utilizing indexing and spray cells, using both sinusoidal and square wave pulse units with pulse times in the microsecond range. Reduced porosity and resistivity of PC coatings was confirmed, but, in contrast to earlier contributions, improved wear resistance was also reported. Of particular interest was the observation that the use of $\mathrm{PC}$ in nickel pre-plating resulted in a substantial decrease in porosity of the subsequent gold plate.

Successful industrial application of PC electrodeposition wás also reported in a contribution by Rehrig (9), describing the use of an assymetric AC wave form in the high-speed selective gold plating of lead frames and presenting comprehensive accounts of process development and of the evaluation of various commercial gold plating solutions, with particular reference to the bondability characteristics of deposits.

In conclusion, this first symposium on the subject can be rated as most successful, attracting as it did an attendance of over 200 and offering a well-balanced technical programme. There seems little doubt that with the increasing commercial availability of suitable PC supplies, particularly in the microsecond range, and with continued research, further interesting and useful development of this technique is to be anticipated, both in precious and base metal deposition.

\section{References}

1 A. J. Avila and M. J. Brown, Plating, 1970, 57, (11), 1105-1108

2 A. Knödler, 'Electrodeposition of Gold Alloys from Acid Solutions by Pulse Plating', Symposium paper

3 H. Y. Cheh, F. Electrochem. Soc., 1971, 118, (4), 551-557

4 N. Ibl, J.-Cl. Puippe and H. Angerer, Surf. Technol., 1978, 6, (4), 287-300

$5 \mathrm{M}$. Branik and R. Schnabel, 'Properties of Hard Gold Deposited by Pulsed Current for Connector Applications, Symposium paper

6 W. Flühmann, P. A. Mäusli, F. H. Reid and S. Steinemann, 'Effect of Pulsed Current Plating on Gold-Cobalt Electrodeposits', Symposium paper

7 C. J. Stimetz and J. J. Hren, 'Pulse Plating of Hard Gold Electrodeposits', Symposium paper

8 F. H. Leaman and B. A. Kownacki, 'Pulsed vs. Direct Current for Continuous Plating of Contacts for Electrical Connectors with Nickel Underplating and Cobalt Hardened Gold', Symposium paper

9 D. L. Rehrig, 'High Speed Selective Gold Plating of Lead Frames for Microelectronic Packaging', Symposium paper 